Brief note

\title{
STUDY OF THE EFFECT OF COMPOSITE CONSTRAINED LAYERS IN VIBRATION DAMPING OF PLATES
}

\author{
K.S.K. SASIKUMAR* and S. SELVAKUMAR \\ Department of Mechanical Engineering \\ Kongu Engineering College \\ Erode, Tamilnadu, INDIA \\ E-mail: ksksasikumar@rediffmail.com \\ K.P. ARULSHRI \\ K.P.R. College of Engineering and Technology \\ Coimbatore, Tamil Nadu, INDIA
}

\begin{abstract}
To add damping to the system, viscoelastic materials (VEM) are added to structures, in order to enhance damping effects of the VEM, a constraining layer is attached. Due to the addition of the material on the system the fundamental characteristics of the systems are altered much. This paper analyzes the damping effect of the constraining layer on plate type structures numerically using the FEM software ANSYS. Experiments are conducted to validate the analytical results. The use of weightless composite materials as constraining layers has been analyzed. Results are compared with the conventional constraining layer materials. The results showed that composite materials give a better damping effect without much altering the fundamental characteristics.
\end{abstract}

Key words: vibration, composite, viscoelastic, plates.

\section{Introduction}

Vibration characteristics of a structure are governed by the mass, stiffness, and damping of the structure. The stiffness is related to the static deformation of the structure. The mass and the stiffness together influence the natural frequencies of the structure. So the design of damping to the structure is most important in relation to the weight of the system. The early studies on the vibration and damping effects of beam and plate structures with a constrained layer damping (CLD) were presented by Kerwin (1959), Ross et al. (1969) and Mead and Markus (1969). Marcelin et al. (1992) analyzed partial coverage of beams. Yan et al. (1972) developed an analysis including longitudinal and rotary inertia in all layers and shear strain in the outer layers. Recently, Fasana et al. (2001) investigated mode shapes, frequencies and loss factors by means of the Rayleigh-Ritz method and with the application of polynomials as admissible functions. Douglas and Yang (1978) modified the model for different applications. The performance of viscoelastic PCLD (Passive Constrained Layer Damping Treatment) can be maximized by a proper choice of materials and geometry. This could be achieved by using some optimization methodology as given by Hao (2005), Lam (1997), and Nakra (1998). Sasikumar et al. (2011) analyzed the effect of constraining layer on the damping of beam like structures.

\footnotetext{
* To whom correspondence should be addressed
} 
This paper investigates the effect of new constraining layer materials such as composites in plate type structures. Further, the FEM and experimental method on the measurement of vibrations damping is provided. The effect of the constraining layer material on vibration and noise reduction is discussed in terms of physical parameters such as loss factors.

\section{Materials and methods}

A steel plate of $356 \times 356 \times 2 \mathrm{~mm}$ was considered for the FEM study and experiments. A composite constraining layer made of E-glass fibre was bonded on the surface in different patterns. Various patches such as 1 patch $(120 \times 120 \mathrm{~mm})$ at the centre of the plate, 4 patches $(72 \times 72 \mathrm{~mm}), 6$ patches $(52 \times 72 \mathrm{~mm})$ and 9 patches $(52 \times 52 \mathrm{~mm})$ were bonded on the surface of the plate so as to control the various bending modes of the plate. The patch location was selected such that the centre of the patch is the nodal point for that particular mode. The patches were bonded with equal distances. Material properties of E-glass fibre composites are given in Tab.1. The base plate is steel with Young's modulus $210 \mathrm{GPa}$ and density $7850 \mathrm{~kg} / \mathrm{m}^{3}$. The aluminium properties are: Young's modulus $70 \mathrm{GPa}$ and density $2700 \mathrm{~kg} / \mathrm{m}^{3}$. The frequency-independent VEM properties are assumed in case studies. The density is $1000 \mathrm{~kg} / \mathrm{m}^{3}$ and the complex shear module is $1 \times 10^{5}(1+i) \mathrm{N} / \mathrm{m}^{2}$.

Table 1. Material properties of E-glass fibre.

\begin{tabular}{|c|c|c|c|}
\hline Properties & Value & Properties & Value \\
\hline Elastic modulus $E_{X}=E_{y}(\mathrm{GPa})$ & 15.70 & Poisson ratio in plane $x-y v_{x y}$ & 0.15 \\
\hline Elastic modulus $E_{z}(\mathrm{GPa})$ & 7.85 & Poisson ratio in plane $x-z v_{x z}$ & 0.46 \\
\hline Shear modulus in plane $x-y G_{x y}(\mathrm{Gpa})$ & 2.45 & Poisson ratio in plane $y-z v_{y z}$ & 0.46 \\
\hline Shear modulus in plane $x-z G_{x z}(\mathrm{Gpa})$ & 2.37 & Density $\mathrm{kg} / \mathrm{m}^{3}$ & 1610 \\
\hline Shear modulus in plane $y-z G_{x z}(\mathrm{Gpa})$ & 2.37 & & \\
\hline
\end{tabular}

\section{Fem study using Ansys}

The configuration of the plate used is cantilever. To make this configuration one edge of the plate was constrained in all the three directions. The element used for the base plate and viscoelastic layer was SOLID 45 and SOLID46 element was used for the composite constraining layer. Figure 2 shows the solid model of the plate with 9 patches bonded on the surface of the plate. After convergence study the total number of elements used are 9032.

\section{Experimental setup}

Specimens are prepared as per the dimension used in the FEM study. These specimens are glued on the surface of the plate by using Araldite resin. The FFT analyzer (ADASH VA4300 MODEL) is connected to the accelerometer and impact hammer (Kistler). The accelerometer was fixed at a specified point on the plate as shown in Fig.1. The impact hammer is struck at a specified point, from which amplitude and displacement values are measured. The obtained values are transferred to the PC and graphs are plotted for comparisons by using the FFT software. 

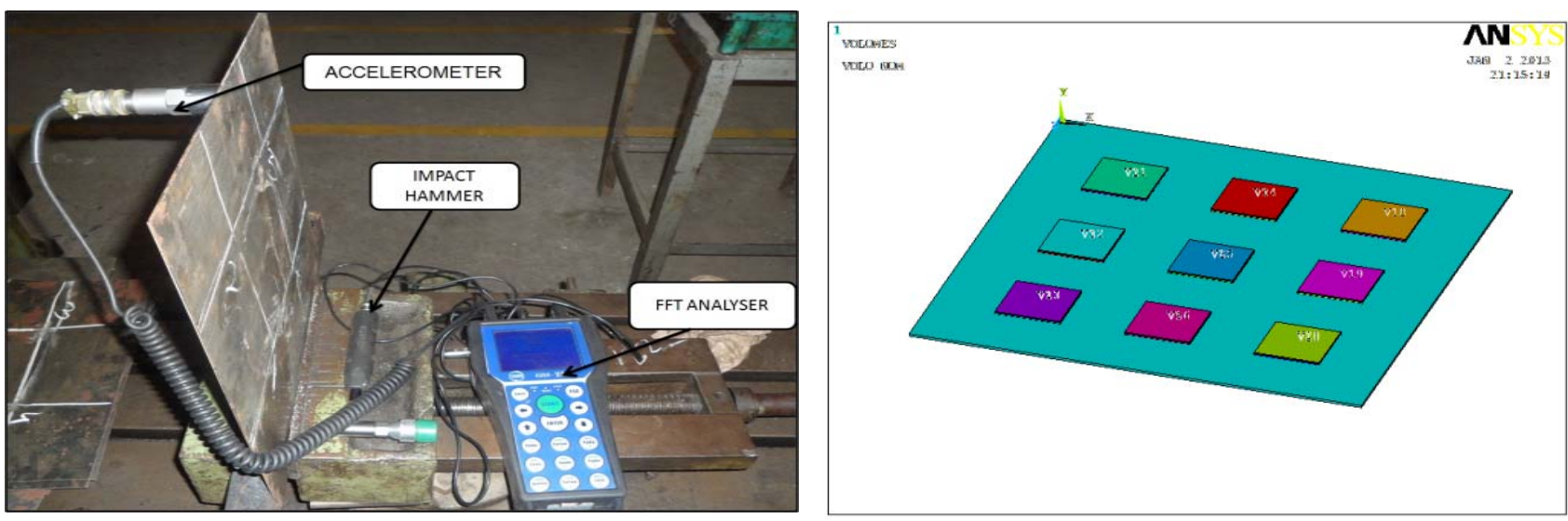

Fig.1 Experimental setup for plate.

Fig.2 FEM volume of the plate with 9 patches.

Figure 3 shows a cantilever plate treated with constrained layer damping treatment of one patch. The materials used for this treatment is steel, aluminium and composite (E-glass fibre).

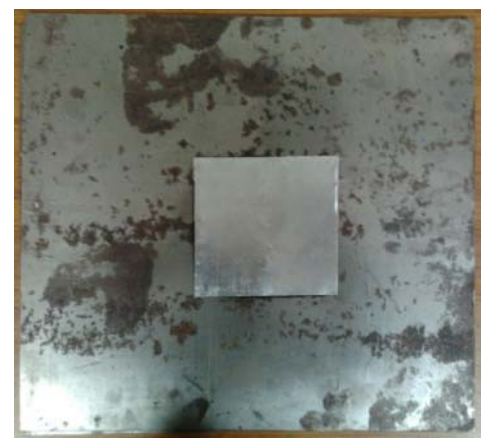

(a)

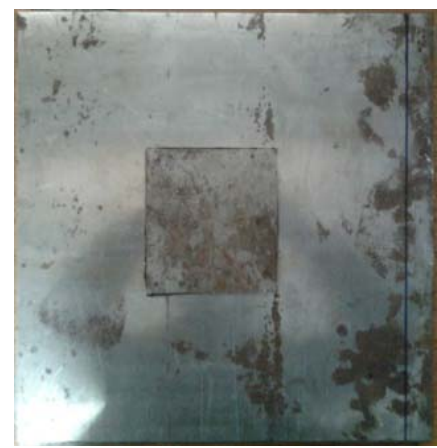

(b)

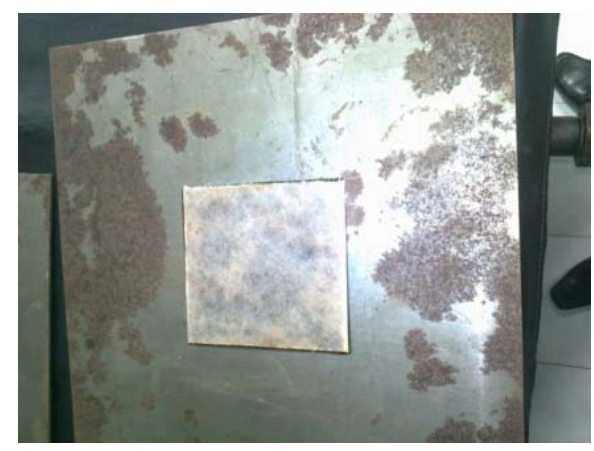

(c)

Fig.3. Steel plates with one patch CLD (a) aluminum (b) steel (c) composite.

\section{FEM and experimental results}

Figure 4 gives the sample FRFs obtained from the FEM and experimental study for the plate with 1 patch CLD and an untreated steel plate. From that graph it is evident that the peak amplitudes at resonance are reduced considerably for the plates treated with constrained layer damping treatment. It can also be seen from the figure that the treatment consisting of steel constraining layer shows a better reduction in amplitudes compared with aluminium constraining layer patches. This can be attributed to the stiffness of the steel constraining layer. From the simulation study, when the aluminium constraining layer was used the vibration attenuation is $31 d B$ in the higher modes and $5 d B$ in the lower mode, whereas the steel constraining layer patch has reduced the vibration $47 \mathrm{~dB}$ and $15 \mathrm{~dB}$ in the higher and lower modes, respectively. From the experimental results the attenuation level of the vibration for the aluminium constraining layer is $16 d B$ and $5 d B$ in the higher and lower modes, whereas for the steel constraining layer the attenuation is $33 d B$ and $15 d B$ in the higher and lower modes. The amplitude reduction for the case of the composite constraining layer is $25 d B$ and $12 d B$ from simulation results. The experimental results for the plate with the composite constraining layer also yielded the same results. 


\section{Loss factor calculation and comparison}

The calculation of the damping factor and loss factor is done by bandwidth method. The damping factor is determined for the first four mode shapes of the plate with different treatment as shown in Fig.5. The loss factors for the plate type structures with a conventional constraining layer such as aluminium and steel are compared with the composite constraining layer so as to prove its effectiveness in damping the structure.

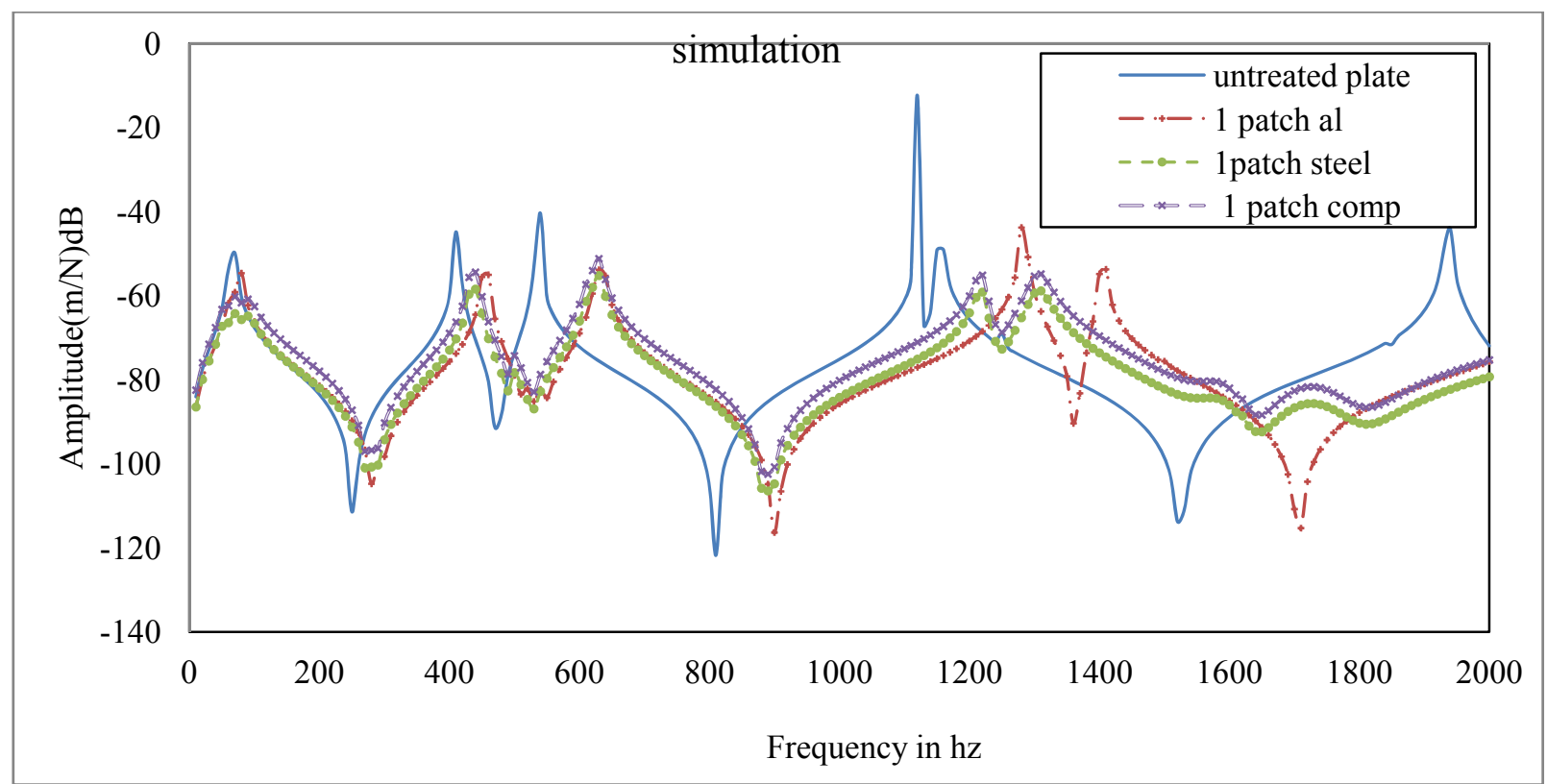

(a)

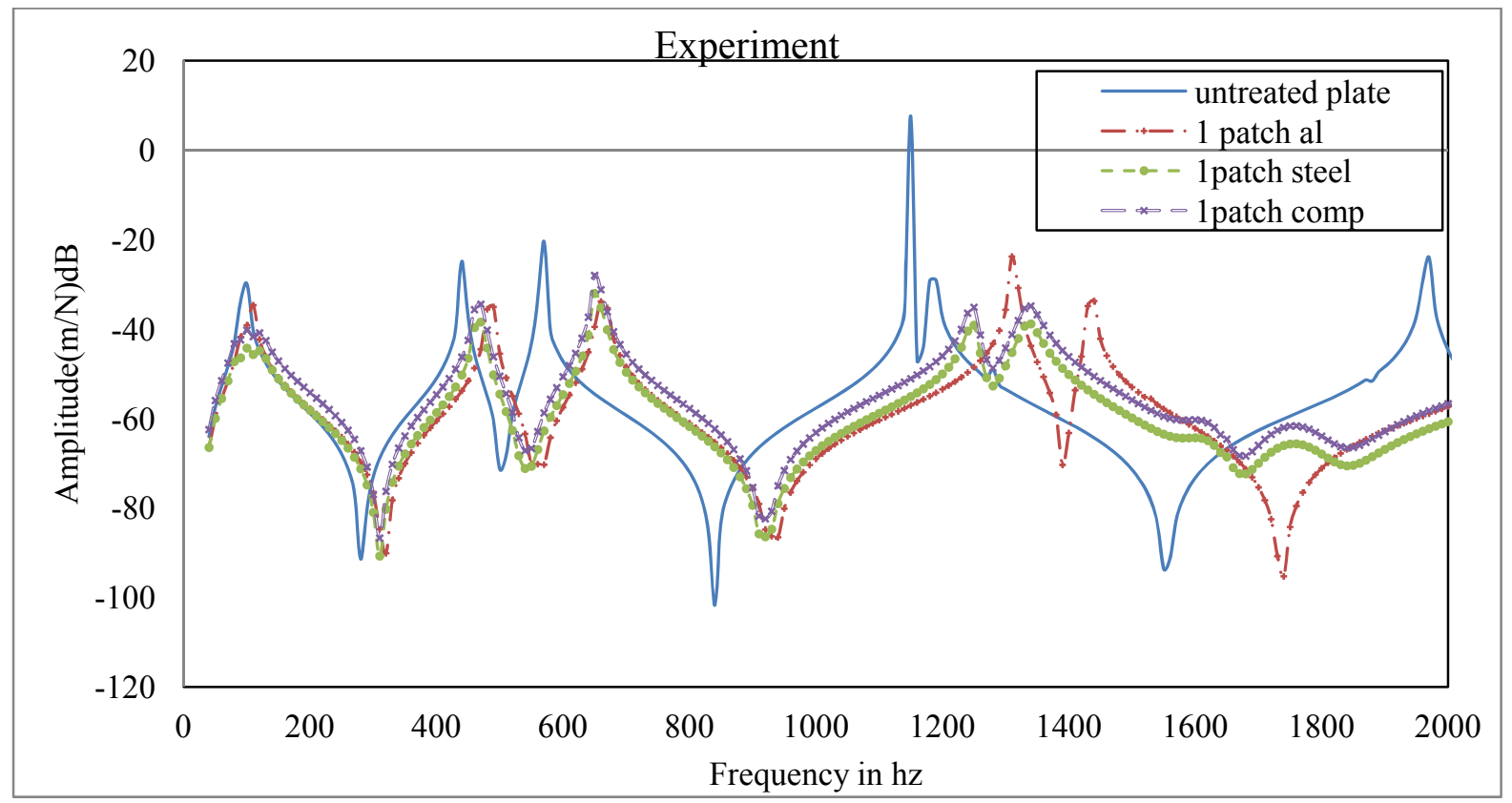

(b)

Fig.4. Frequency response function of untreated steel plate with 1 patch aluminum and steel CLD (a) Simulation (b) Experiment. 


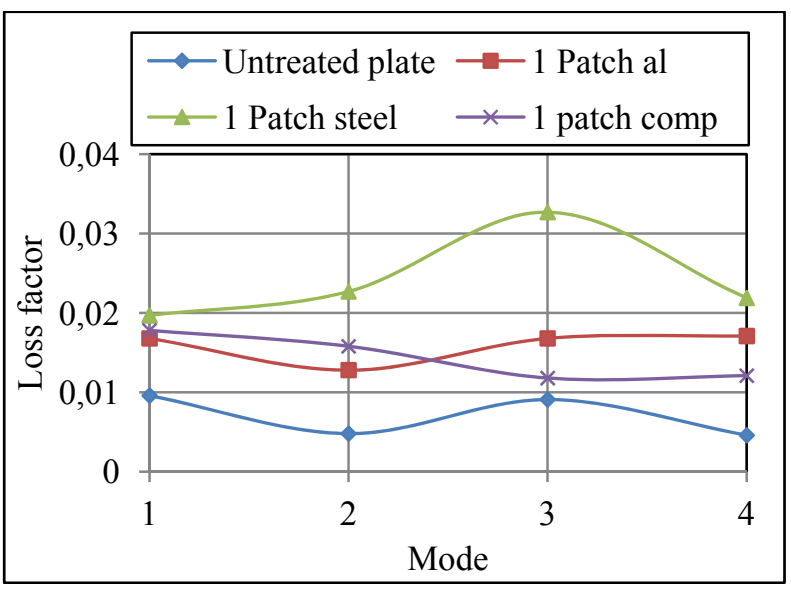

(a)

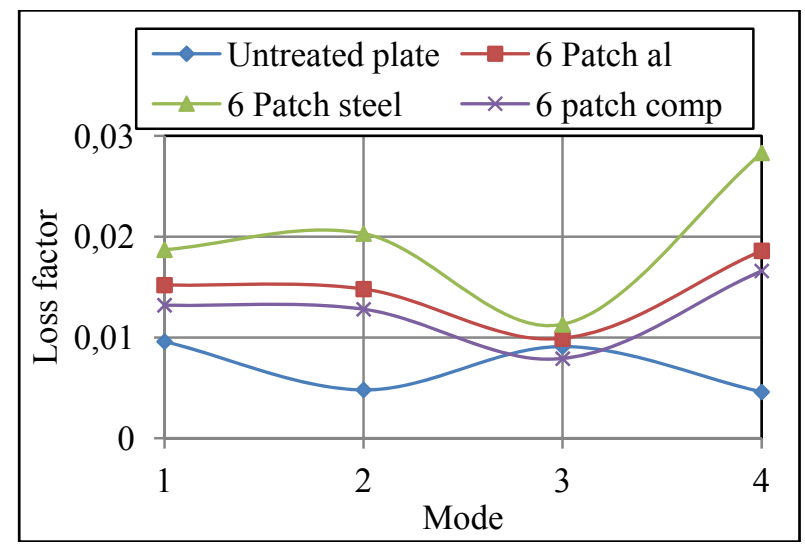

(c)

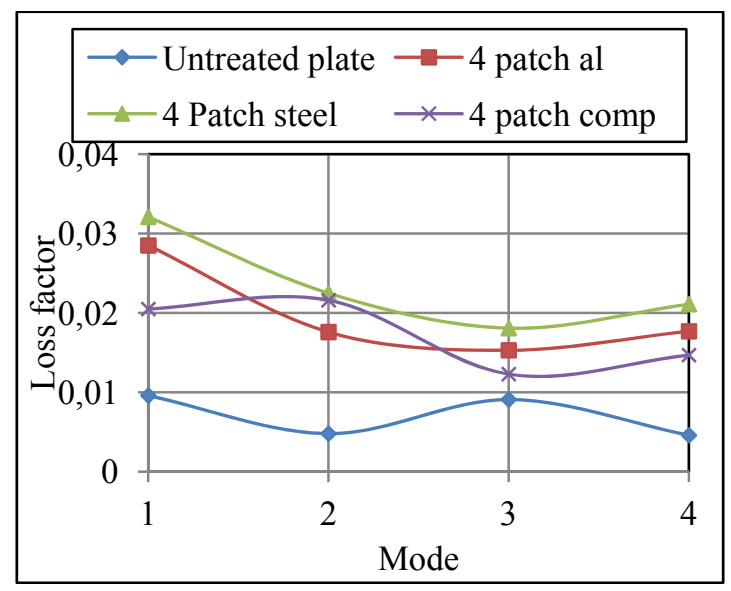

(b)

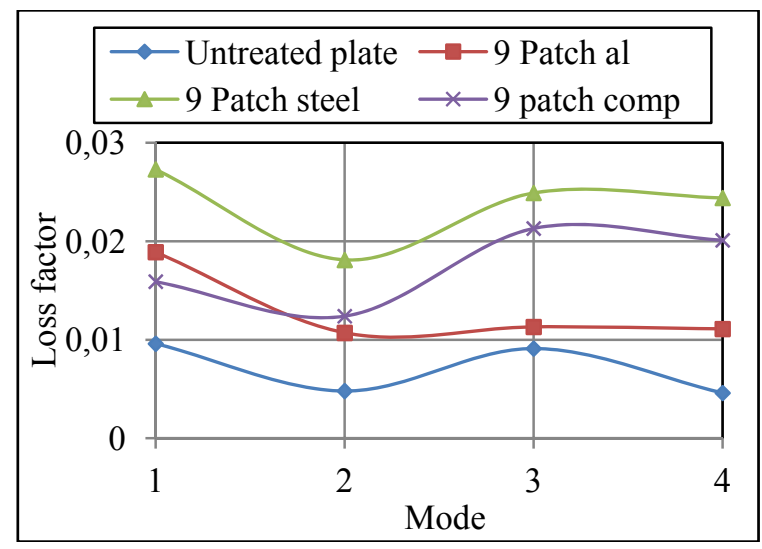

(d)

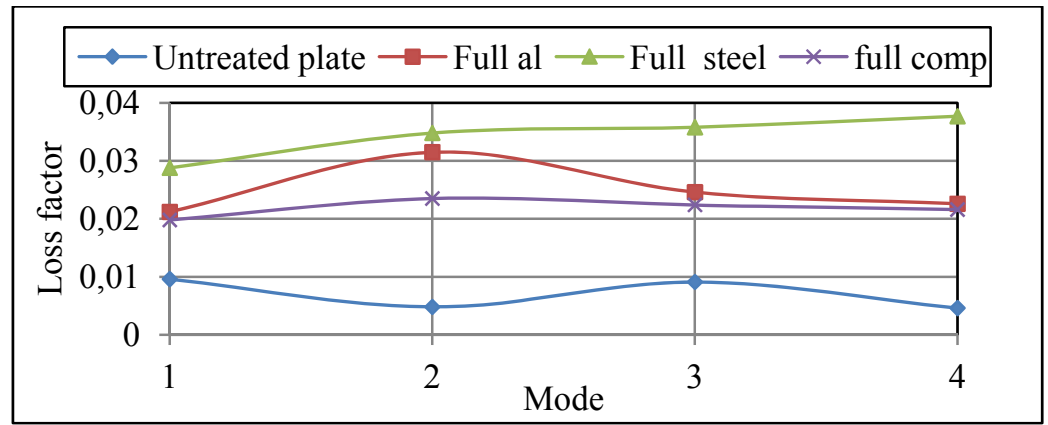

(e)

Fig.5. Loss factor graph for different patches and untreated steel plate obtained from FEM study (a) one patch (b) 4 patches (c) 6 patches (d) 9 patches (e) full patch. 
Figure 5 a-e compare the loss factors for the steel plate with 1 patch, 4 patches, 6 patches, 9 patches and full CLD and untreated steel plate found from the FEM study using the frequency response function. When the stiff constraining layer, say steel, is used it suppresses vibration more effectively. The composite constraining layer provides better damping than the aluminium constraining layer but less than the steel constraining layer with less weight penalty.

\section{Effect of added mass on the system performance}

A summary of PCLD treatment is shown in Fig.6. The partial constraining layer offers more weight efficient damping to structures. Whenever there is no concern about added weight full coverage damping gives better damping performance. The overall treatments can be applied as splitted one at the appropriate positions on the plate so as to control the different modes of the vibration as required. For this prediction of the node and antinodes is required.

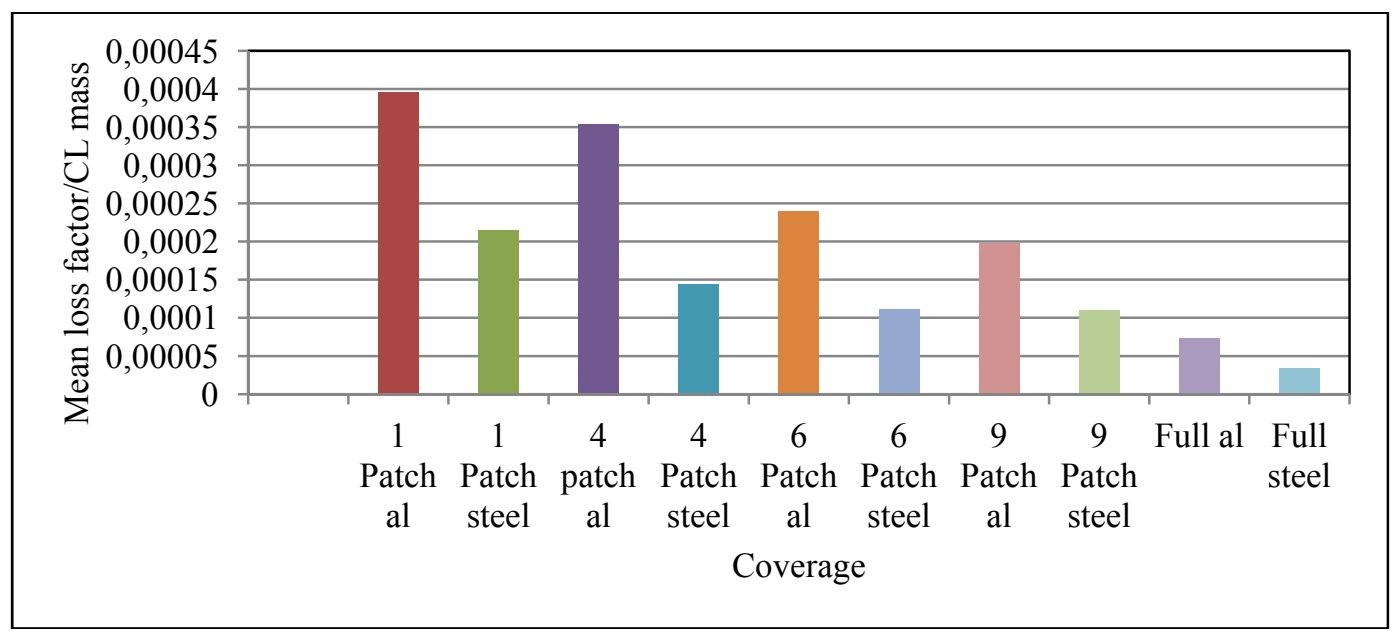

Figure 8.19 Mean loss factor comparison

\section{Conclusions}

A finite element procedure has been formed to predict the damping characteristics of plate type structures attached with constrained layer damping treatments. Various sizes of constrained layer damping patches were prepared and bonded on the plate to control the different modes of the plate. Using the developed finite element code, the plate with different treatments was analyzed. An experimental procedure was also generated and followed to test the plate with damping treatments. A good correlation was observed between the FEM results and experimental results. From the extensive analysis it was found that the stiffer constraining layer produced better damping when compared with the less stiff constraining layer. It was also found that the fundamental frequencies of the systems were affected due to the addition of added weight to the system. Bonding of patches at different locations over the surface of the plates effectively suppresses the particular modes of vibration of the plates. The patches should be fixed at the high strain portion of the plate.

\section{References}

Douglas B.E. and Yang J.C. (1978): Transverse compressional damping in the vibration response of elastic viscoelastic beams. - AIAA Journal, vol.16, No.9, pp.925-930. 
Fasana A. and Marchesiello S. (2001): Rayleigh-Ritz analysis of sandwich beams. - J. Sound Vib., vol.241, No.4, pp.643-652.

Hao M. and Rao M.D. (2005): Vibration and damping analysis of a sandwich beam containing a viscoelastic constraining layer. - Journal of Composite Materials, vol.39, No.18, pp.1621-1643.

Kerwin E.M. (1959): Damping of flexural waves by a constrained viscoelastic layer. - Journal of Acoustic Society of America, vol.31, No., pp.952-962.

Lam M.J. (1997): Hybrid active/passive models with frequency dependent damping. - Ph.D Dissertation. Virginia Polytechnic Institute and State University.

Mantena P.R., Gibson R.F. and Hwang S.J. (1991): Optimal constrained viscoelastic tape lengths for maximizing damping in laminated composites. - AIAA J., No.29, pp.1678-1685.

Marcelin J.L., Ph. Trompette and Smati A. (1992): Optimal constrained layer damping with partial coverage. - Finite Elements Anal. Des., vol.12, No. pp.273-280.

Mead D.J. and Markus S. (1969): The forced vibration of a three-layer, damped sandwich beam with arbitrary boundary conditions. - AIAA Journal, vol.10, No.2, pp.163-175.

Nakra B.C. (1998): Vibration control in machines and structures using viscoelastic damping. - Journal of Sound and Vibration, vol.211, No.3, pp.449-465.

Ross D., Ungar E.E. and Kerwin E.M. (1959): Flexural vibrations by means of viscoelastic laminate. - ASME Structure Damping Section, pp.48-87.

Sasikumar K.S.K., Selvakumar S. and Arulshri K.P. (2011): An analysis of the effect of constraining layer modulus on the vibration control of beams treated with PCLD. - European Journal of Scientific Research, vol.66, No.3, pp.377391.

Yan M.J. and Dowell E.H. (1972): Governing equations for vibrating constrained layer damping of sandwich beams and plates. - J. Appl. Mech. Trans. ASME, vol.94, No., pp.1041-1047.

Received: January 3, 2013

Revised: November 6, 2013 